\title{
Duality in Urban Development: Marginalisation of City Tribes
}

\author{
Dr. Purobi Sharma \\ (Department of Political Science, Cotton College State University, Assam, India)
}

\begin{abstract}
The Paper, Duality in Urban Development: Marginalization of city tribes is an analytical assessment of the contextual specific in an urban situation. In the context of a rapidly growing city in the North East India there is a constant unfolding of a society towards urban way of life due to ever expanding migration process in a backward economy. In this process though there is steady growth of economy and high literacy rate in the city, the original inhabitants lag behind the process of urban development .Traditionally they were the land lords and possessed vast amount of land in and around the present city. The expansion of the city meant shedding off their land rights to the migrated people being deprived of substantial monetary benefit. Their status has been studied as a marginal group despite being the land lords .Land has gradually become a major issue of their survival in the city. The study finds that their original traits remain strong. It is an investigation of lack of belongingness in the emerging urban situation and is a modest attempt to focus attention on the intricate problems and facets of development process of cities.

Key words: apathy, deprivation, isolation, land status, new vitality, urban tribes.
\end{abstract}

\section{Introduction:}

The growth of urban centers carries with it strong waves of social changes encompassing structural and cultural entities. It is a strong current of accumulation as well as elimination of societal forces. It is particularly so in a situation of unfolding of an isolated geographical area in a peripheral region. The North East part of India in its historical context represented a tribal society with off and on infiltration of diverse cultural elements. Political ups and downs, socio-cultural turmoil, economic restructuring and exposures to tides of national integration -all are triggering factors of alteration and diversification of societal forces in the NE region of India. Urbanization process is bedrock on which many structural changes rest. Lack of Institutionalized norms and proper policy create lag in the process in the developing societies. The process of urbanization in developing societies is not marked by balanced impact on the community structure. ${ }^{[1]}$

Urbanization process in North East India has its own traits determined by the historical, physical, demographic, economic and socio- cultural characteristics of the Region. Guwahati, the rapidly urbanizing city of the region in its evolution from a tribal society to a primate city with political patronage has witnessed all such waves of social changes. ${ }^{[2]}$ In this process, the indigenous tribals have been pushed away from their original lands in the focal centers of the city. Guwahati, with its regal -ritual historicity has grown as a major center of migration in the Region. ${ }^{[3]}$ The city is one of its kind, at least in India with its distinctive physical character; with a large stretch of the mighty river Brahmaputra flowing through it, surrounded by hills on all sides and a vast plain in between. This type of physiographic setup casted an exceptional impact upon the socio - cultural milieu of the people of Guwahati; which is a particular character of the developing counties, as opposed to the developed world, where a planned approach is adopted for the growth of an area.

The early British historians straight away rated this area as unfit for urban development and even a poor set up for civilization because of hot and humid climatic conditions and damp, swampy and low lying shallow landform. However because of its strategic location, Guwahati gradually started to gain importance. In the entire northeast India it has acquired special significance as it acted as the gateway to the entire region. It is so positioned that it virtually faced the western or urban world of rest of the country of that period; specifically Calcutta, which was the British hub with typical urban quality.

\section{Theoretical Context}

Life in a city has been conceptualized and it has also been given a context specific basis with structural guidelines by the United Nation agencies. Sociological understanding on the process of urbanization has been expressed through theories on its social sources and consequences. George Simmel in his article "The Metropolis and Mental life" offered one of the first theories of relationship between urbanization and societal forms, characterized by anonymity. ${ }^{[4]}$ Ferdinand Tonnies also developed the theory of impersonal relations based on business exchange and the close-knit community based on warmth and intimacy. ${ }^{[5]}$ 
Robert Park and his followers developed the idea of marginal man to express a situation of duality in the social world in the process of adaptation and unfolding of social changes. He described the marginal man as "cultural hybrid, a man living and sharing intimately in the cultural life and traditions of two distinct peoples; never quite willing to break, even if he were permitted to do so, with his past and his traditions, and not quite accepted, because of racial prejudice, in the new society in which he now sought to find a place. He was a man on the margin of two cultures and two societies, which never completely interpenetrated and fused. Cultural bounds of our narrower society become to some extent marginal men." ${ }^{,[6]}$ The question of urban marginality has been addressed by many scholars leading to manifold direction of its interpretation and application adding the extended ideas of new marginality. ${ }^{[7]}$ Chad Alan Goldberg, a professor of sociology at the University of Wisconsin-Madison, reviewed the development of the concept of marginal man in American sociology. This review comprehensively highlights the extended scholarly works on Park's notion of the marginal man beyond his focus on race and ethnic relations to a broader range of social phenomena, including occupations, gender, and scientific innovation. Contemporary sociological interests in globalization, immigration, cultural hybridity, and multiculturalism, have further renewed the concept in recent years. ${ }^{[8]}$ The term urbanism was coined by Louis Wirth to refer to ways of life in cities. Wirth published a classic essay on this theme "Urbanism as a Way of Life", in the American Journal of Sociology in 1938. In this essay he focused on city life, minority group behaviour and mass media. His research was concerned with how Jewish immigrants adjusted to life in urban America, as well as with the distinct social processes of city life. Wirth long back answered the question of scholarly fascination towards marginality in the context of rapid social change. Wirth noted, where there is greater mobility and more "contact between diverse racial and cultural groups" than in the past, "all of us are men on the move and on the make, and all of us by transcending the cultural bounds of our narrower society become to some extent marginal men., ${ }^{[9]} \mathrm{He}$ applied the concepts and theories of sociology to study of city life. For those who followed Wirth' s ideas, the way of life of urban areas has been a more important subject of study in the process of urbanization. Looked at from this perspective, a country may have high degree of urbanization but in terms of culture its urban areas may not be very different from the rural areas. Alternatively, urbanism needs to be defined varyingly in the context of different countries. The history and processes of growth of the urban areas in the two world regions acquire different characters, or different styles of urbanism. ${ }^{[10]}$

Researches may be conducted on urban marginality in diverse platforms of disparity in the urbanization process. The present work is not directly concerned with the process of Urbanization which refers to growth of urban population, in relation to rural population. It touches some aspects of urbanism which refers to presence of a distinctive culture in urban areas. In undertaking investigation of a local context of marginal situation associated with urban development process to understand genesis and management of urban precarity, three aspects of these theoretical understandings have been taken into account: one, the growth process of a city goes beyond the demographic and spatial expansion, it is an environment of overall transformation process of the society. Lack of belongingness of some original groups may lead to urban apathy. Second, the structural realities are associated with a complex situation of making resources available to urban dwellers, use of urban space also mean denial of opportunities to some. Third, within a varied context of urban divide, urban marginality may be understood as a concept of adjustment and insecurity as well as a situation of dualistic realities at structural levels.

UN agencies and centers throw ample light on the urban way of life, hinting towards the positive and the negative trends. UN-Habitat has repeatedly focused on the city as a place where social and political life takes place, knowledge is created and shared, various forms of creativity are developed, cultivate societal values and a way of getting access to resources, culture and various forms of riches or well being. ${ }^{[11]}$ There is also emphasis on the fact that the city denies opportunities for some. Cities can therefore be places of inclusion and participation, but they can also be places of exclusion and marginalization. Urban trends as an inevitable worldwide process has been generally positive. It is expected to bring fundamental changes in the employment sector; in societal values and modes of governance; in the configuration and functionality of human settlements; extension of democratic rights and empowerment. In this context, different modes of marginalization can be studied for theoretical formulation. One such segment may be the original landlords and the aboriginals who also may be marginalized. It is an investigation is of the scenario of the aboriginals being marginalized; lagging behind the emerging urban way of life; not being part of the process though they are living in the city throughout the process of its evolution and growth. The growth process of the city has been a major motivation to consolidate their group identity and to find out survival strategies in an urban world. 


\section{Methodology}

With the growth process of the legal city the tribal groups have emerged as one of the segments of the city. The paper analyses the status of these groups in the urban setup. City tribes, in this paper are those people who were the original inhabitants in the city having their own land. They were gradually pushed back to the hilly walls of the city. Within the prime functional areas some pockets have been categorized as slums. While investigating the impact of urban development process on the tribal people, inhabitants in the core and peripheral areas of the city since past has been taken into consideration. These two categories have been surveyed to know the differences in their status as urban dwellers. Extensive household survey has been conducted in the tribal pockets and data has been collected through long interview sessions. The sample size considered here is about 10 per cent of the total population of these tribal communities. Investigation is based on specific enquiries on life skill and life style of the people living in different parts of the city. For this purpose, demarcation of the functional urban areas in the original municipal area and the present metropolitan area has been made. The survey extended a period of six months during 2012/2013.

\section{Background}

The chronology of growth of Guwahati can be divided into three distinct phases; ancient, medieval and modern. And according to the clues derived from the historical records the aborigines of Guwahati, residing since the most ancient period were tribals; although it is difficult to estimate the exact time of early human settlement in the area. They were scattered all over the region, but at some definite pockets; because they were the people who could put up with the unfavourable habitable conditions of the place. They led a simple life basically involved with indigenous agriculture in the plain areas, and gathering and lumbering from the surrounding woodlands and hills; and sufficed their need following barter system coordination among themselves which is still prevalent in some areas.

The medieval period was very significant as the process of immigration of people from all around began. It was an extensive period where Aryans from west (rest of India), Mongoloids from north and east (rest of North East) and the British who were the colonial rulers of the country entered the region gradually at different durations. Thus the phase of arayanization and colonization grew in Guwahati and the conversely the alienization of the original inhabitants initiated. The post independence period can be referred to as the modern period of urban growth in Guwahati which is still continuing. Today the demography of the city has changed totally acquiring a new appearance, the process of which actually began in the medieval period itself.

The population of Guwahati accounted for $23.3 \%$ of the total urban population of the state of Assam. The urban population within the Guwahati Metropolitan Area according to the 2011 census is 968,549 . The educational facilities in the city are provided by a large number lower, middle and higher level educational institutions. It is the education core of the whole North East Region. Average literacy rate of Guwahati city is 91.11 percent of which male and female literacy rates are 92.89 and 89.16 percent respectively. This indicates a rich socio-cultural life in the city. Guwahati is the most important trade hub in the North Eastern Region. The major economic activities are trade and commerce, transportation and services. The gross domestic product of Guwahati metro was estimated at $\$ 1$ billion in 2010. At present the quarterly average household income of Guwahati is around Rs.70, 000 which is more than the country's average household income of Rs 50,000.

\section{Land Scenario}

Historically the occupancy pattern in the city was marked by a great divergence between the tribal and non tribal areas. The non-tribal areas were the seats of religious, administrative and commercial activities. Occupancy pattern was totally determined by the migration pattern at different phases. A strongly fortified city was created due to emergence of new power groups consolidating their status in the city. The convenient location on the river bank transformed Guwahati into a significant administrative and military seat. The emergence of an urban class was confined chiefly in the small stretch along the old core area (Bharalu to Guwahati club). The rest of the areas were occupied by the Karbis, Bodos, Rabhas, Kacharis, Kukis and other tribal groups. As per the 2001 census there were 23 different indigenous tribal communities in the state which has increased to 25 according to the 2011 census with a variation of 17.4 percent increase than the last. Also there has been a continuous trend of immigration of tribal population from the rest of the North East states to Assam. In this context the tribal scenario in the city is a reflection of the overall scenario of Assam.

Tribal representatives have raised voice at the state level platform that the boundaries of the tribal belts and blocks should be delineated through proper survey. Moreover, the Government should go for carving out new tribal belts and blocks to cover the new tribal habitations. There should be strict legal provisions to prevent leasing out of land belonging to the tribals. Tribal Belts and Blocks is a product of the colonial 
policies which had created special provisions for various protected groups including "tribes". It refers to certain compact areas of Assam predominantly inhabited by tribal and other backward people notified under It was prepared with the ostensible objective of protecting land from occupation by other advanced groups other than the ,protected class of people -Plains tribals, Hills tribals, tea garden tribals, Santhals, Scheduled Castes and Nepali cultivator graziers. Later indigenous Koch-Rajbongshis of Goalpara, Dhubri, Kokrajhar and Bongaigaon districts were added under this category. It was a misnomer, , to use the phrase "tribal belts" because others groups are also involved ${ }^{[12]}$ They express that a commission of inquiry with a retired judge as its head and tribal representatives as its members should be instituted to go into the cases of illegal land transfer. The Government should re-appoint the eight Additional Deputy Commissioners who were specially appointed to look into the Chapter-X of the Assam Land and Revenue Act and the Government should include representatives of the Tribal groups and the chairmen of the Sub-divisional Tribal Development Boards as members in the sub-divisional land advisory committees proposed to be set up. The resentment is also over the non-inclusion of any representative of the tribals in the land advisory committee formed by the State Government during the eviction drives. ${ }^{[13]}$

Land scenario since middle of the last century could be obtained by the records of the District Commissioner' s Office which show that $80 \%$ of the land transaction in non reserved areas was between tribals and non tribals. Vast agricultural land in the east and west side of the city was gradually occupied from tribals for residential purposes. Gradually the occupancy pattern was changed with the inclusion of more and more tribal inhabited areas into the orbit of Guwahati. The present focal residential and commercial centres were to a large extent tribal occupied lands where tribal societies had the full expression of their group life and social interactions.

Land Market and the brokers pushed back the aboriginals to hills. The process of shifting of tribal pockets from inner circles to the outer circles of hilly areas was started. A continued process but now a different picture of marketing has taken place .Land value increases considerably every year according to the land market mechanism but due to unawareness the tribal inhabitants cannot make out the benefit concealed within it. Though Govt. of Assam had a land policy but the authority i.e. the District Commissioner do not ascertain use of allotted land on the purpose it was allotted. Non implementations of Tribal Belt regulations are a strong factor of displacement and deprivation of city tribes in the present time.

The Greater Guwahati area was under the South Kamrup Tribal Belt prior to the shifting of the State capital to Dispur. To shift the State capital and to expand Guwahati city, the area falling under the South Kamrup Tribal Belt was de-reserved. This uprooted the sons of the soil from their native places. For, many of the tribals did not have land pattas (ownership records) and they were not conscious of the need of land pattas. Those who were evicted from their native places in the name of establishment of the State capital, State Zoo, military cantonment, oil refinery, etc, are still subjected to eviction. Moreover, many of the tribal people settling in many areas of the city have not been able to secure their land pattas, as they are not in a position to pay the premiums fixed by the Government for the purpose.

The Government is also denying land pattas to many tribal families settling in the HengrabariBarbari grazing reserve for decades. The argument of the Government in this respect was that these people were settling on a grazing reserve land. But the same area has been allotted to some influential people later on. The palatial buildings built by these influential people have been causing flash floods in Hengrabari area. The land advisory committee set up for allotting land to the landless people in Guwahati should consider the matter seriously. The amount of premium required for allotment of land should be halved in the cases of the tribals, the tribals should be granted land pattas wherever they are residing and the tribals, who are living in the forest areas and the fringe areas of the forests, should be granted land rights as per the provisions of the 2006 Right to Forests Act. ${ }^{[14]}$

\section{Empirical Analysis:}

The tribal communities from whom this land was alienated were deprived of their livelihood because most of them lived in a natural resource based informal economy that depended on the one hand on settled agriculture and on the other on the non-timber forest such as medicinal herbs, edible flowers, leaves and fruits. They also got their small timber and firewood from the forest. Hence city growth affected their agricultural and forest land which was the primary source of their livelihood. The development process pushed them from primary to secondary and tertiary economies leading to urban precarity. They depended on agricultural land and forests, both of which they lost to the migrants. They received compensation in monetary form with which most communities living in the informal economy were not familiar. Money was not spent in productive purposes or for qualitative growth. It acted as the prime factor responsible for slow growth of Urbanism among them.

The city was developed as an inner core of all urban functions: administration, trade and education. 
Political patronage was always part of it tribal pockets within the core area are mostly slums though they are residing in their own land. Within the demarcated city area of Guwahati the major tribal zones are Lakhra, Hengerabari, Manipuri Basti, Kachari Basti, Beltola Market, Birubari/Nijora Par, Beltola Mouza, Hati Garh, Borbari, Ulubari Mouza, Gorchuk, Jyotikuchi, Betkuchi . The chief tribes residing in these areas are the Karbis, Bodos, Kacharis, Manipuris, Garos, Deuris and Rabhas. Karbis constitute the highest share of the tribal population (41\%), followed by Bodos $(25 \%)$ and Kacharis $(9 \%)$. The Deuris $(3 \%)$ and Rabhas(3\%) comprises the lowest concentration. A very keen observation here arises that, unlike the major cities of India where there exists a main stream - sub stream relationship between the elite and underprivileged; in Guwahati that kind of association actually subsisted between the tribal and the dominant communities. Land transformation into a high value market asset did not occur in Guwahati. Throughout the years tribal displacement has taken place in the city particularly in the east and south directions which are parts of the proposed new township under Masterplan Guwahati-2025, prepared by the Metropolitan Development Authority. There is a strong indication of the continuity of the pushing back process of the tribal people from these areas also. In the present study investigation was carried in tribal pockets which retained tribal ownership in a consistent manner

People living in and around this area since past, have different experiences of land occupation as they were subject to frequent displacement due to legal measures without any move for their rehabilitation. Social suffering of the tribes is enhanced by continuous flow of outside groups, mostly immigrants from Bangladesh. The picture obtained from the city reserve forest known as Amchang show the needs of state intervention in matters related to such issues. In 2004 Amchang was declared a Wildlife Sanctuary having 78.64 sq. km area. There were only 5 small villages---Ekrabari. Sowali lukuwa Sal, Shyam Pather, Hatishila and Kilinghop inside Amchang before it was declared sanctuary. Several thickly populated settlements ---Garobasti, Hastinapur, Kangkan Nagar, Pragati Nagar, Malagog etc. are part of it. Political patronage is evident and eviction drives have no impact on illegal settlers. Law prohibits human settlement within prohibited areas. As per official data, 860 hectares, mostly of the khanapara reserve forest, are under encroachment. In 2002 it was 500 hectare. Home to diverse fauna including 44 species of mammals and over 250 species of birds, Amchang offered every opportunity to be developed as protected area. Given its proximity to the city, Amchang could have emerged as an ideal Tourist Spot, especially for hiking and trekking. This is an indication of the plight of city tribes around the reserve forest as they are frequently displaced from their dwelling places. Similar trends are also observed in the reserved forests within the limits of Guwahati Municipal Corporation, such as Hengrabari, Phatasil and Jalukbari which are under the administrative control of the Divisional Forest Officer, Kamrup (East) Forest Division. Deepar Beel, which is a vast expanse of water body on the western side of the city, is another recently declared Wildlife Sanctuary within the municipal area of Guwahati where same issues have again cropped up.

\section{V.Nature Of Marginality}

Several indicators have been selected to find out the level of adaptability of urban way of life by the city tribes. The land status, exposure to urban life, social relationships, political participation, provision of infrastructure, mode of utilizing wealth obtained from land, role of the community rituals and habits are the major areas of investigation.

The picture of Literacy pattern, one of the most important features of urban society, is highly contrasting among these indigenous tribes and the non-tribal population of the city. Although a relatively low percentage of people are totally illiterate, but the rate of growth of literacy is very low among the tribals. Further, some amount of disparity also prevails in the literacy pattern of the tribal people residing within the inner core of the city and its outer core. The tribal pockets of the inner core such as Kachari Basti (Ulubari), Manipuri Basti (Paltan Bazar) are comparatively in a better state of literacy than the tribal zones found beyond this functional city area, which clearly indicates their locational significance, engulfed within the city. Primary education level among the people is good enough because of the Government schools in their localities. However, it has been observed for a period of time that there is a high tendency among the students to either drop out from the schools or even somehow is deficit of the potential to carry on with the curriculum. The economic condition of the people, their socio-cultural background, the lack of interest and also the endogamous community life are the main factors responsible for this lag. The youths tend to abandon their studies and get involved in livelihood practices which are again of very low means. There are very few students from these pockets who seek admission in the colleges and go for higher education. Guwahati has gradually been developed as an education hub in the entire North East with the literacy rate being $91.9 \%$. Whereas the indigenous tribal students are practically missing from the scenario, in the sense that they are neither eligible to take admission in the prime institutions which require high marks nor have the drive towards that. In general and vocational educational institutions, out of the total tribal students almost 94 $\%$ are from outside the city and have actually migrated from other parts of north east. In private institutions 
also their absence is conspicuous. No consistency in the pattern of enrollment in secondary level education. Again there is a slight contrast between these people who live in the inner city and outer city zones. In the considered survey sample, it has been found that although very few people among these tribes are totally illiterate, $7.8 \%$. Although not highly educated, most of the people have attained their primary education, $44.56 \%$ and also a considerable percentage has gone upto attaining secondary or college level but is of very poor quality. Higher education among the people even though negligible, is not absent, (Graduates 9.76\%, Post Graduates $0.87 \%$ ); which totally belongs to the inner city zone.

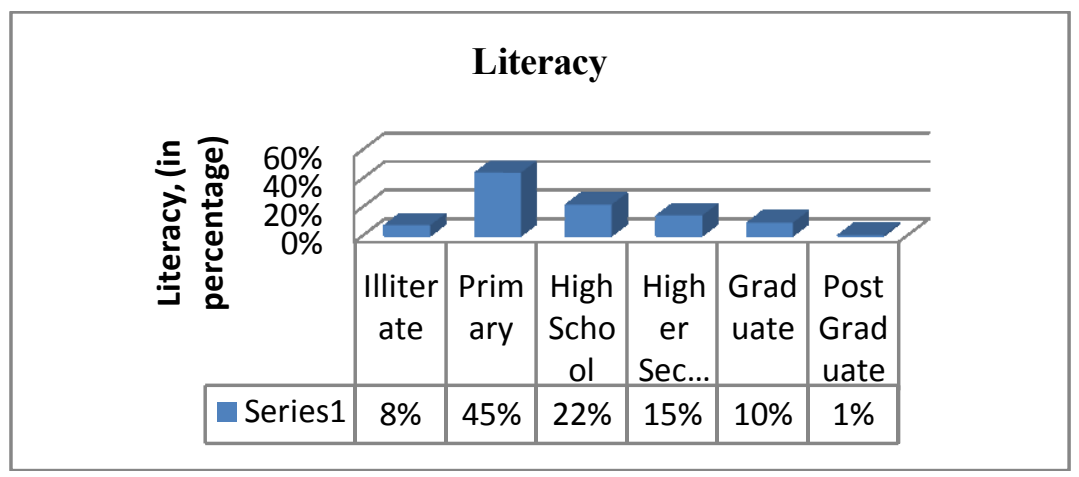

Figure: 1

Almost all the people of the considered sample reside in their own land, where the nature of land holding is inherited for majority of the households (39\%). The ownership of the land has also been attained by purchasing from the tribals $(17 \%)$ and also fellowmen (17\%). A considerable section of people has also gained the ownership of the lands, only since they have been occupying it since a long period of time (22\%). Half ownership (5\%). The status of family property is perpetual. Maximum proportion of the households has inherited their lands from their ancestors (41\%). About $23 \%$ have purchased their present day habitable land as agricultural lands. First generation occupancy of the household property (purchased and registered) constitutes about $18 \%$. A substantial portion of community ownership of the household property is also prevalent, (12\%). Remaining $6 \%$ has been simply occupied by the families and owned subsequently.

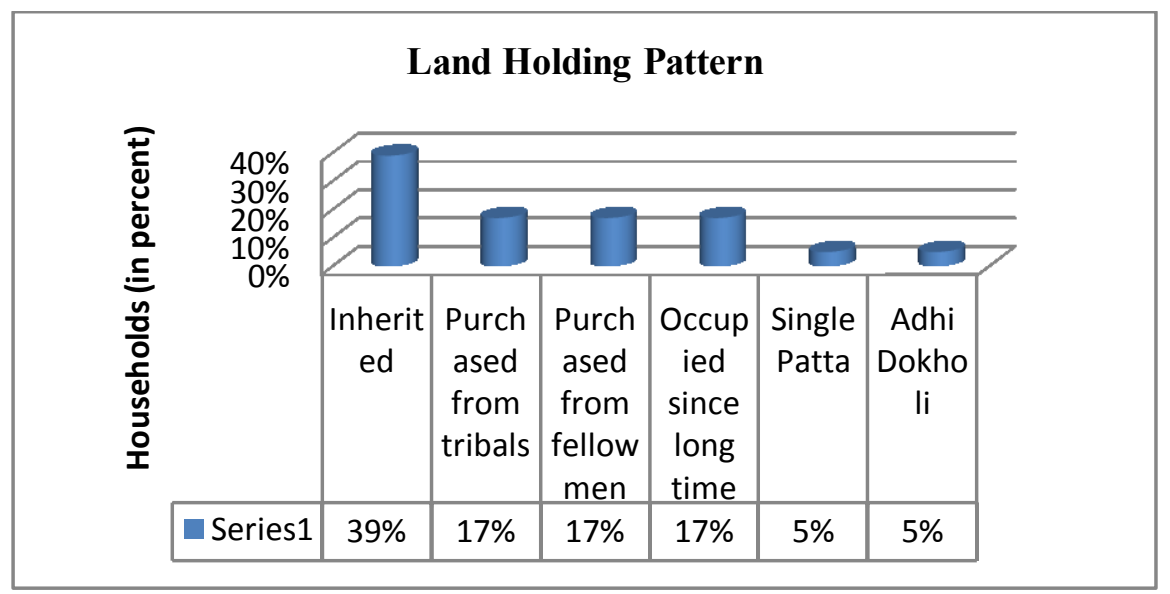

Figure: 2

Integration/Isolation level in the city, reveal a mixed picture and most of the respondents adopt a reluctant view. $53 \%$, of the surveyed people view themselves as development deprival specifically due to social and economic reasons, whereas the other $47 \%$ still think that they are equals. Around $90 \%$ of the people have strong social, political and religious linkages with their fellow tribesmen living outside the city, other than the people within their zone; as compared to the local people of the dominant communities in the city. A strong tendency of apathy is evident in their responses towards city management system - Nearly all the people are aware of their tribal identity, but not even less than half wants to retain it (36\%). More than $60 \%$ of the people want to do away with their tribal status and assimilate with the local people or the dominant community of the society. It has also been found that above $60 \%$ of them don' t use their original languages in informal conversations anymore, even among themselves. Majority of the households practice group life, mostly temple or Namghar centric. Their societies are mostly 
governed by tribal courts and Gaon buras (Village Headman). Their group lives also revolve around their different indigenous religious practices, ceremonies, collective community works, clubs etc. Besides they even practice many rituals of the dominant social groups of the city.

Extended interviews were taken to gain insight of the men and women; their thought process refuses to deal with the risk of being marginalized, rather their total activity is basically dominated by alcoholism. More than $80 \%$ of the people believe that there is no threat to their existence and identity in the growing urban situation of the city. They feel that, they are actually benefitted from the ongoing process of urban development which has. Again conversely they are able to sense the intimidation about the new land holding pattern, (60\%); although a good percentage is not even bothered about it, (35\%) and $5 \%$ remains complacent. Yet again, around $25 \%$ of the people still think that they are same as before in regard to urban development, and there is no development since generations. They have both positive (32\%), Negative (31\%) as well as Very Bright (37\%) expectation/ anticipation about the future of the city.

Political participation among the people is also limited. About $40.72 \%$ of the surveyed sample aspire important role in politics but lack exposure to actually participate. But another $54.21 \%$ do not bother about political participation and in fact, lacks interest. The remaining 5.07\% aspires political leadership to some extent. It has also been seen that majority of then follow group dictation in important matters, $63 \%$. Only $11 \%$ take individual decisions and about $26 \%$ follow group dictation partially to some extent. The people lack the urge of leadership and thus there are very less leaders among them. Most of the people have no or very less expectation in regard to land holding, No $-53 \%$, to some extent $-35 \%$. Only about $12 \%$ of the people think positive about it. In this context it was found that the influence from outside is limited till now and therefore the issue has not been politicized in magnitude.

It has been interestingly noted that the present occupational pattern of the working population is dominated by business (Small shops in the localities, weekly markets etc), 44\%. A comparatively less number of people are engaged in pure agricultural activities $28 \%$ whereas previously it covered almost $75 \%$. About $20 \%$ are engaged in services, ( mostly private sector, very few government employees, mainly fourth grade) which has increased from a mere $13 \%$ previously. Daily wage earners consist of only $4 \%$ and the remaining $4 \%$ are engaged in other informal activities.

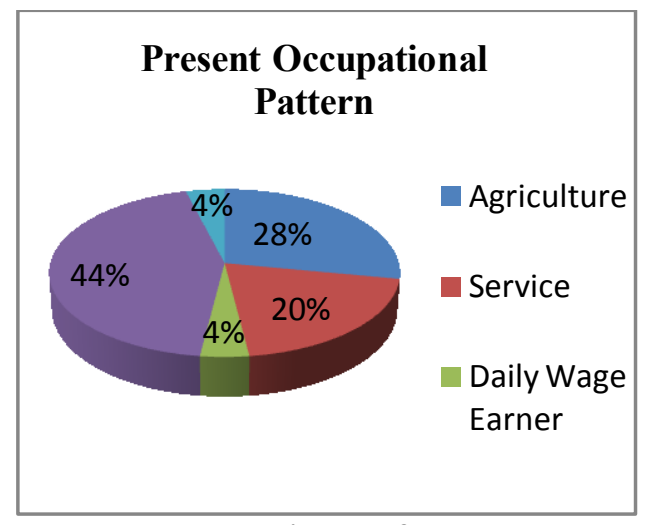

Figure: 3

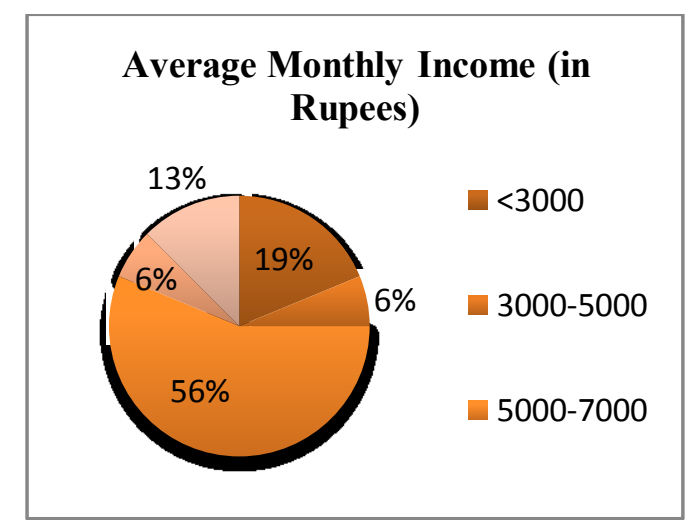

Figure: 4

Average monthly income of the surveyed household sample has been classed taking a suitable interval with respect to the pattern observed. The number of households falling below the lowest mark, Rs. 3000 is $19 \%$. Highest percentage of people is covered in the range 5000-7000 and the lowest in the classes $3000-5000$ as well as $7000-1000$. It was also found that about $13 \%$ of the people earn more than 10,000 per month, comparatively higher.

The most striking face is the poor provision for urban infrastructure in tribal blocks and total negligence for creation of a strong urban base for use of infrastructure. The poor pictures of environmental issues are the major indicators of lack of growth of urbanism in the clusters of tribal residences. No leadership has emerged among them to raise the issue of deprivation. To study the standard of living and provision of amenities among the city tribes, demarcation of core and peripheral areas have been made. Urban Infrastructure in the realm of drinking water, sanitation, electricity, schools, health facilities and housing there is variation among the people within the study area.

Almost $60 \%$ of the slums in the peri-urban, hilly areas are inhabited by tribal groups. A few decades ago the areas around the hillocks were covered with dense forest, tall trees and wild bushes. However, with the pressure of increase in population, these forests were burned and cleared, the hillocks were cut down and the plain agricultural lands were filled up for building houses and commercial shops. There are several Reserved Forests in and around Guwahati. The forests act as the green lung of Guwahati, but, 
unfortunately, a large chunk of the area is encroached by unauthorized occupants who are mostly tribes displaced from other parts of the city. Participation of the people living in and around the hills and forests in the city is poor in the city development process. In the peripheral pockets the people live in an indigenous style adopting community housing which although is non urban but is not poor. But in the inner core the scenario is slightly contrasting, almost a slum like condition prevails there with poor infrastructure and housing facilities.

The carrying capacity of the urban local body in respect of urban amenities and services suffer due to non inclusion of vast hilly areas in revenue earning zones. As a result these areas remain outside the purview of municipal services. Similarly in the core areas lack of municipal holding numbers, lead to insufficient services in comparison to size of population. Being deprived of basic civic amenities, these overcrowded under serviced areas of urban conglomeration develop the trend to turn into slums. These settlements need minimum basic services like adequate water supply, hygienic sanitation, scientific drains, electricity, housing etc. in order to improve the environmental conditions of the city as a whole. This needs serious attention of the urban policy makers.

According to the survey almost $72 \%$ deliveries in these slum areas were conducted at home. Immunization rates were particularly poor. Only $43 \%$ children in the city in the age group 1-2 years were covered with complete doses of immunization and in slum areas tot al coverage was only $31 \%$. Almost $40 \%$ of children were without a single dose of vaccination. There was a conspicuous lack of medical services for these people. The main thrust of the programs envisaged under the, slum improvement therefore, must be designed to address gaps in service delivery by providing appropriate services to improve maternal and child health in these slum areas. The evidence suggests that city mangement authorities faced with rapid urban development lack the capacity to cope with thee diverse demands forr infr astructural provision to meet needs of urban tribes grouped as urban poor in slum areas. $\mathrm{F}$ urther deterioration of the situation will lead to proliferation of the slums in the city.

A case study is presented to indicate the nature of economic activities of a large group residing in the city since the historic period. The area named Beltola is a major functional hub of the present city. Since past Beltola mainly consisted of the Garos, Karbis, Lalungs, Rabha and Kacharis while small numbers of Koch, Kalitas, Ahoms, Manipuris and Muslims later came and settled in Beltola. Historically the area has rich cultural heritage of Koch kingdom and Ahom patronage. In the later period the area became a great conglomeration of migrated people. Commercial houses and business activities are the nerves of the urban life in this part of the city. In this process of urban growth the local tribal population faced immense threat for their existence due to the settlement of large number of people from different parts of Assam. the presence of indigenous tribal people has been maintained in the historic Beltola haat or Beltola Bazar, resisting some outside business communities who tried to expel them. The historical Beltola haat or the beltola bazaar still retains the indigenous character of being a meeting point for the people from hills and plains .Commercial pursuits in terms of marketing their products are very vibrant in this area but the community has remained as indigenous without improving educational status.

Impact of urban development is totally limited in the economic upgradation of the community. As such the whole concern in the ongoing urbanization process has been concentrated in the socio- cultural aspect. They are under threat that they may be forced to adopt an alien urban culture. We have found that more than $75 \%$ of the tribals in the past were dependant on sustainable use of land and forest resources. Once deprived of their livelihood they made a transition from their traditional economic activities to a destructive dependence on flow of money. It lead to a frustration resulted in severe alcoholism. In our interview sessions $90 \%$ of the households who got some amount of money from selling of land used it for domestic consumption. Some of the old people while regretting such matters commented that the younger generation in their community began the production of country liquor at home which became their primary source of livelihood. Drunkenness has reportedly increased tremendously leading to a carefree lifestyle and low motivation for urban work culture.

Externally they are not in the central business activities of the city. They have not been able to take part in ever expanding commercial activities. In the inner city zone the informal sector has their presence. In the outer zone agricultural pursuits are still very vibrant. Internally the life style is not experiencing many changes. The group solidarity and total commitment towards indigenous customs and culture dominate their life pattern. The waves of modern education and technology of outside world are far away from them. This is an indicator of the level of isolation from the other segments of the city society and the gap has been maintained throughout the years The Community' $\mathrm{s}$ understanding of their own marginalization is articulated from their experience of marginality in the ever expanding magnitude of urban situation. Clearly obvious is their resignation. They have become almost habituated to their conditions over generations. 


\section{Conclusion: The New Marginality}

Ample literature on the concept of marginality suggests rethinking and reconstruction of the concept in the light of changing structural situations. In our context an important dimension of the situation is that in the prevailing political situation of North East India, where newer demands of autonomy and assertion are constantly made, tribes in the city could have projected themselves as vulnerable site and situation of instability. Our investigation of the awareness level gives a picture of limited responses at the city level, since the city tribes are not directly involved in ongoing political movements of the North East Region of India. Lack of politicization of their issues has created a distinct situation for the city tribes. Another two significant observations are: in the pursuit of maintaining their original life style in the tribal inhabited areas, the city has been given a different wear in comparison to rising slums in other parts of the city. Again, the bond between the tribal groups and the other local people are rising due to growing expansion of the city leading to more proximity. Marriage alliances in recent times have opened up new ways of assimilation. In this context, a futuristic approach would suggest some distinct trends - one, assertion of their urban status with gaining ground the opportunities; second, adjustments towards urban way of life and third, creation of a platform of economic vitality within the available resources.

A new middle class, though not very distinct have entered into services whereby an assertion within development platform has been established. Cross cutting linkages of heterogeneous affinity the trend towards a homogeneous identity in terms of basic assertions is emerging. Tribal identity will enhance colour with the reframing of their existence within a unified criteria of development. Knowing the language of assertion of belongingness the city tribe as termed in this paper will stand as a distinct entity and may attain a new identity of being the urban tribes. The new urban marginality as suggested by Loic Wacquant will result not from economic backwardness, sluggishness or decline, but from rising inequality in the context of overall economic advancement and prosperity. ${ }^{[15]}$ Consequent to it a totally vibrant and positive picture also could be drawn in which the situation may unfold itself for economic viability. The tribal pockets in the hills and outskirts have very good potentiality to be developed as indigenous tourist spots to provide eco friendly centers of attraction .Urban development management system has to gear it up. This would give a new dimension to the prime city of North East India.

\section{Referances}

[1]. State of the World' scities, 2010/2011, Bridging the urban divide. First published by Earthscan in the UK and USA in 2008 for and on behalf of the United Nations Human Settlements Programme UN-HABIT AT. Pp. 4-30

[2]. Sharma Purobi, 2013 Genesis of a City: Urban Development in Guwahati, Eastern Book House , Guwahati, (to be published, PhD thesis, Urban Development in a Developing society, p. 52)

[3]. ibid.

[4]. Simmel Georg, 1903, "The Metropolis and Mental Life", in Gary Bridge and Sophie Watson, eds. The Blackwell City Reader, Oxford and Malden, MA: Wiley-Blackwell, 2002.p11-19

[5]. Tonnies Ferdinand, 1957, Community and Society: Gemeinschaft und Gesellschaft translated and edited by Charles P. Loomis, pp. 223-231. Copyright, The Michigan State University Press.

[6]. Park, Robert, 1928: "Human Migration and the Marginal Man", The American Journal of Sociology,33 (6): pp. 881-937.

[7]. Weisberger, Adam, 1992 "Marginality and Its Directions" Sociological Forum 7(3): pp. 425-446.

[8]. Goldberg Chad Alan, 2012, Laboratorium, Robert Park' s Marginal Man: The Career of a Concept in AmericanSociology, Issue 3.http://new.soclabo.org/index.php/laboratorium/pages/view/subscribe

[9]. Louis Wirth, 1938, Urbanism as a Way of Life, The American Journal of Sociology, Vol. 44, No. 1, pp. 1-24. The American Journal of Sociology is currently published by The University of Chicago Press.

[10]. Wirth, Louis. [1948] 1964. "Consensus and Mass Communication" Pp. 18-43 in On Cities and Social Life, edited by Albert J. Reiss, Jr. Chicago: University of Chicago Press.

[11]. State of the World Cities, 1012/2013, Prosperities of cities, UN Habitat, UNHSP, 2012 pp8-28

[12]. Under Chapter X of the Assam Land and Revenue Regulation (ALRR) Act of 1886 that was amended in 1947 on the basis of the recommendation by a committee headed by Mr. Hockenhull.

[13]. Information obtained from office of the Tribal Sangha, an active group, it issues press releases.

[14]. Interview sessions with the tribal groups in the city during November, 2012.

[15]. Wacquant Loic, 1999 Urban Marginality in the Coming Millennium ,Urban Studies, Vol. 36,No. 10, pp.1639 1647 